\title{
RE DRYING OF BLACK TEA BY USING DEHUMIDIFIED AIR
}

\section{BY}

\section{P.A. Nishan Darshaka Perera}

M. Sc 


\section{Re Drying of Black tea by using dehumidified Air}

\section{By}

\section{P.A. Nishan Darshaka Perera}

Thesis submitted to the University of Sri Jayewardenepura as the partial fulfillment requirement for the award of the degree of Masters of Food Science and Technology.

Department Of Food Science and Technology,

Faculty of Applied Sciences,

University of Sri Jayewardenepura,

Sri Lanka. 


\section{Declaration}

The work describe in this thesis was carried out by me under the supervision of Professor Arthur Bamunuarachchi, Department of food Science and Technology, faculty of Applied sciences, ,University of Sri Jayewardenepura, Sri Lanka and the report on this thesis has not been submitted in whole or in part of any university or institute for another degree .

Date. 25. 01.2014

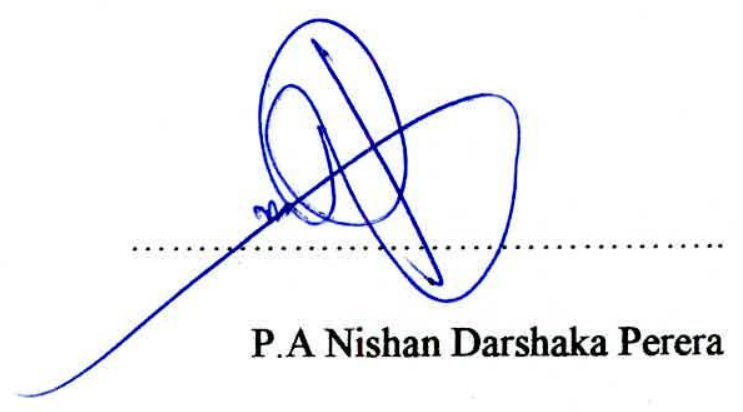


I certify that the above statement made by the candidate is true and this thesis is suitable for submission to the university for the purpose of evaluation.

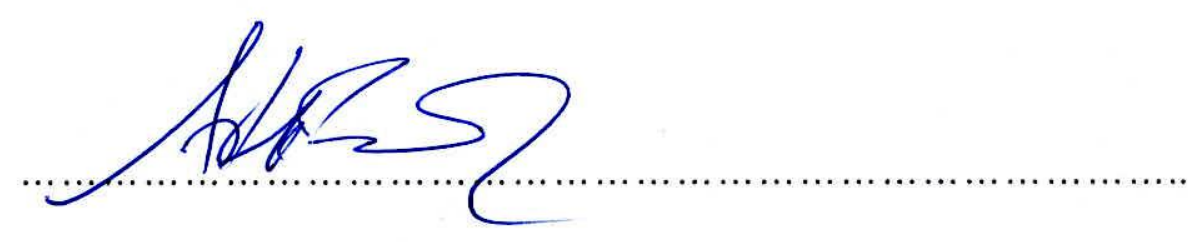

Professor Arthur Bamunuarachchi,

Department of food Science and Technology,

Faculty of Applied sciences,

University of Sri Jayewardenepura,

Sri Lanka 


\section{Table of Contents}

$\begin{array}{lc}\text { Table of contents } & \text { Pages } \\ \text { List of Tables } & \mathrm{i} \\ \text { List of figures } & \mathrm{v} \\ \text { List of Plates } & \mathrm{vi} \\ \text { Abstract } & \mathrm{vii} \\ \text { Acknowledgement } & \mathrm{ix} \\ \end{array}$

\section{CHAPTER 1}

Introduction

1.1. Objectives

1.1.1. General Objective

1.1.2. Specific Objectives

\section{CHAPTER 2}

\section{Review of Literature}

2.1 Tea drying 5

2.1.1. Drying - changes in the tea particles 6

2.1.2. Drying - types of dryer 8

2.1.2.1. Endless Chain Pressure Dryer 8

2.1.2.2. Basic fluid bed dryer 10

2.2 Sorting 11

2.3 Storage and packing 11

2.4 Qualities of teas 11

$\begin{array}{ll}\text { 2.4.1. Moisture absorption of made teas } & 13\end{array}$ 
2.4.2. Equilibrium moisture content

2.5. Sensory and the organoleptic propertise of the tea 16

2.6. Dehumidification Drying 16

$\begin{array}{ll}\text { 2.6.1. Methods of removing moisture } & 18\end{array}$

2.6.1.1. Cooling-based Dehumidification $\quad 19$

2.6.1.2. Desiccant Dehumidifiers 20

2.6.1.3. Different types of desiccant dehumidifiers 24

2.6.1.3.1: Liquid spray-tower 25

2.6.1.3.2. Solid packed tower 27

2.6.1.3.3. Rotating horizontal bed $\quad 30$

2.6.1.3.4. Multiple vertical bed $\quad 32$

2.6.1.3.5. Rotating Honeycomb 33

2.6.1.4. Comparing desiccant dehumidifiers 35

\section{CHAPTER 3}

\section{Materials and Methods}

3.1. Research Location 37

3.2. Selection of Raw materials 37

3.3. Dehydration by using conventional fluidized bed dryer 37

3.4. Dehydration by using dehumidified air 38

3.4.1. Laboratory Trial 38

3.4.1.1. Effect of the drying temperature of drying black tea 38

3.4.1.2 Determination of Equilibrium moisture content of tea 39

3.4.1.3 Study the relative Humidity Variation with different

$\begin{array}{ll}\text { Processed air Temperatures } & 40\end{array}$

3.4.1.4. Study of Processed air out against the different

processed air in temperatures. $\quad 42$

3.4.1.5 Calculation of moisture reduction over the period of time. 43 
3.4.2. Pilot Scale trial 43

3.4.2.1. Horizontal continuous drying chamber with fluidized bed 44

3.4.2.2. Vertical Tower type dryer 45

3.4.3. Manufacturing and Fabricating Industrial Unit 47

\section{CHAPTER 4}

\section{Results \& Discussion}

4.1. Dehydration by using conventional fluidized bed dryer $\quad 50$

4.2. Drying by using dehumidified air 51

4.2.1 Laboratory trial $\quad 52$

4.2.1.1. Effect of the drying temperature of drying black tea 52

4.2.1.2. Determination of equilibrium moisture content of tea 53

4.2.1.3. Study of relative humidity variation with different

processed air temperatures. $\quad 54$

4.2.1.4. Measurement of process air out temperatures with different processed air in temperatures $\quad 58$

4.2.1.5. Calculation of moisture reduction over the period of time 59

4.2.2. Pilot Scale Trial $\quad 62$

4.2.2.1. Horizontal continuous drying chamber with

fluidized bed action $\quad 62$

4.2.2.2. Vertical Tower type dryer 63

4.2.2.3. Fabrication of Industrial Unit. 67

4.2.2.3.1. Calculation of the amount of moisture need to be removed within the drying period of 2 hours $\quad 68$

4.2.2.3.2. Calculation of the moisture removal capacity of the whole system including the air conditioner as well as dehumidifier model FFB 600 which was selected to couple with the drying bin for drying black tea. 70

$\begin{array}{ll}\text { 4.2.2.3.3. Machine output results } & 71\end{array}$

4.2.2.3.4. Calculation of drying cost per $1 \mathrm{Kg}$ of black tea $\quad 72$ 


\section{CHAPTER 5}

Conclusions

CHAPTER 6

Recommendations

CHAPTER 7

References

Appendices 


\section{List of Tables}

Table 2.1.Tea tasters scoring and comments on made teas from thin layer drying

Table 3.1: Relative humidity calculation sheet with the difference between wet/dry bulb temperatures

Table 4.1: Main sensory property changes between non re- fired tea and re-fired tea

Table 4.2: Variation of sensory properties with the drying air temperature for period of 3 hours

Table 5.3: Change of Equilibrium moisture content with equilibrium relative humidity

Table 4.4: Relative humidity variation for the different processed air temperatures

keeping the reactivation temperature at $100^{\circ} \mathrm{C}$

Table 4.5: Relative humidity variation for the different processed air

temperatures keeping the reactivation temperature at $120^{\circ} \mathrm{C}$

Table 4.6: Relative humidity variation for the different processed air temperatures keeping the reactivation temperature at $140^{\circ} \mathrm{C}$

Table 4.7: Relative humidity variation for the different processed air temperatures keeping the reactivation temperature at $160^{\circ} \mathrm{C}$

Table 4.8: Summary of Relative humidity variation for the different processed air temperatures keeping the reactivation temperatures at $100^{\circ} \mathrm{C}, 120^{\circ} \mathrm{C}, 140^{\circ} \mathrm{C}$ and $160^{\circ} \mathrm{C}$

Table 4.9: Measurement of different processed air out temperatures vs different processed air in temperatures

Table 4.10: Calculation of moisture reduction over the time with air at $30^{\circ} \mathrm{C}$ having the relative humidity of $10 \%$ 


\section{List of Figures}

Figure 2.1 Temperature of leaf versus moisture content of leaves

observed in drying process $\quad 8$

Figure 2.2.Equilibrium moisture isotherms from dew point meter data 15

Figure 2.3: Desiccant vapor pressure variation against desiccant moisture content in sorption, Desorption and cooling

Figure 2.4: Desiccant vapor pressure variation against desiccant moisture content in sorption, Desorption and cooling in liquid spray tower Dehumidifiers

Figure 2.5: Desiccant vapor pressure variation against desiccant moisture content in sorption, Desorption and cooling in solid packed tower dehumidifier

Figure 2.6: Desiccant vapor pressure variation against desiccant moisture content in sorption, Desorption and cooling in Horizontal rotating bed

Figure 2.7: Desiccant vapor pressure variation against desiccant moisture content in sorption, Desorption and cooling in rotating Honey comb dehumidifier

Figure 4.1: The graphical presentation of the variation of the equilibrium moisture content against equilibrium relative humidity

Figure 4.2: Graphical presentation of Relative humidity variation with different processed air temperature

Figure 4.3: Graphical presentation of processed air out temperature variation with different controlled processed air in temperatures.

Figure 4.4: moisture reduction Vs time with air having its temperature of $30^{\circ} \mathrm{C}$ and the relative humidity of $10 \%$

Figure 4.5: Diagram of the prototype plastic drying bin with the moisture contents at various heights. 


\section{List of Plates}

Plate 2.1: Schematic diagram of mass flows in a tea factory 5

Plate 2.2 Diagram of a simple dryer $\quad 7$

Plate 2.3: Schematic diagram of ECP dryer. $\quad 9$

Plate2.4: Schematic diagram of basic fluid bed dryer $\quad 10$

Plate 2.5: Schematic diagram for cooling based dehumidifier 19

Plate 2.5. Schematic psychometric chart shows the cooling system first chill the air to its dew point $-100 \%$ relative humidity. After that point further chilling removes moisture. The more the air is cooled, the deeper it will be dried.

Plate 2.7: Shows, as moisture is removed from the air, its enthalpy stays constant, so its sensible temperature rises. In fact, the enthalpy of the process air - air being dehumidified - actually increases slightly. This is because in many dehumidifiers, a small amount of residual heat from desiccant reactivation can be carried into the dry air:stream.

Plate 2.8: Schematic diagram of Liquid spray tower $\quad 25$

Plate 2.9: Schematic diagram of packed tower dehumidifier 28

Plate 2.10: Schematic diagram of rotating horizontal beds 30

Plate 2.11: Schematic diagram of rotating horizontal beds 32

Plate 2.12: Schematic diagram of rotating Honey comb 33

Plate3.1: Picture of Bry Air dehumidifier 39

Plate3.2: Diagram shows the Air movement through the desiccant wheel 40

Plate 3.3: Diagramme of dry and wet bulb thermometer 41

Plate 3.4: picture of dry/wet bulb thermometer 41

Plate3.5: The set of apparatus used for the laboratory trial 43

Plate3.6: Modified Horizontal continuous drying chamber with fluidized bed 44

Plate3.7: Side and the front view of Vertical tower type pilot drying unit 45

Plate3.8: Complete Diagram of the drying system 46

Plate3.9: Picture of Installed and commissioned developed industrial $\begin{array}{ll}\text { scale tea drying system } & 48\end{array}$ 
Plate3.10: Infra-red moisture meter used to measure the moisture content

Plate3.11: Brick Vacuum pack of dried Black tea

Plate4.1: Picture of the complete set of pilot unit manufactured for the trials

Plate 4.2: Picture of the orange Pekoe Black tea 


\title{
Re Drying of Black Tea ( Camilia synansis) by using dehumidified air
}

\author{
By
}

\author{
P.A Nishan Darshaka Perera
}

\begin{abstract}
Sri Lanka is one of the best quality black tea producers in the world. Black tea is dried or fired until it reaches $3 \%$ moisture content and this preserves the sensory and organoleptic properties of tea. After tea is dried or fired it is exposed to various types of handling operations including grading and sorting, stalk extraction, iron removal, color separation, storage as well as blending. These operations are mostly done in ambient conditions and exposed to the humid air. Since tea is hydroscopic in nature it absorbs the moisture.

Series of experiments and trials were planned and performed to develop an industrial scale re drying method to reduce the moisture content of black tea by using dehumidified air. Dried and moisture absorbed tea was subjected to various types of drying temperatures and found out by sensory evaluation when the temperature below $35^{\circ} \mathrm{C}$ does not alter the sensory or the organoleptic properties of the tea.
\end{abstract}

The ambient air was cooled to different temperatures from $10^{\circ} \mathrm{C}$ to $30^{\circ} \mathrm{C}$ and fed into the dehumidifier to adsorb the moisture in the cooled air. It was found that the lowest temperature of $10^{\circ} \mathrm{C}$ gave the best results of the lowest relative humidity of $10 \%$ at $35^{\circ} \mathrm{C}$.

Two drying methods were carried out, horizontal fluidized bed dryer and vertical bin type dryer. It was found that the bin type dryer consumes less space, lower energy and performs faster drying.

Above conditions, air having $35^{\circ} \mathrm{C}$ temperature and $10 \%$ relative humidity were sent through a tea sample over the period of time and measured the moisture content of the tea every 15 minutes by using infra-red moisture meter. With the above data drying curve was established and found out within $1 \frac{1}{2}$ hours tea can be dried to $4.5 \%$ from $13 \%$.

By using an air conditioner and Bry Air Dehumidifier model FFB 170 coupled to a drying bin and made a proto type, pilot scale system for trials and it gives expected results of reduction of moisture to $4.5 \%$ within 2 hours without altering the sensory and organoleptic properties.

Pilot scale unit was scaled up to a industrial scale unit by using two units of 24,000 BTU Air conditioners and Bry air dehumidifier model FFB 600 and black tea drying bin. Calculations were done to confirm the moisture adsorption capacity of the dehumidifier. 
Industrial unit was developed very successfully and it was capable of handling $960 \mathrm{Kg}$ of black tea and reduced the moisture content from $13 \%$ to $4.5 \%$

It was confirmed that the re dried tea by using cooled dehumidified air does not alter the sensory and organoleptic properties. 


\section{Acknowledgement}

I would like to extend my sincere gratitude to my supervisor Professor Arthur Bamunuarachchi Emeritus Professor, University of Sri Jayewardenepura, Sri Lanka, Consultant Food Scientist and Technologist, Specialist, Agribusiness, Post-Harvest and Food Processing Trainer, for his guidance, coaching, counseling and mentoring throughout my research.

Also I would greatly appreciate the guidance and the encouragements receive from Dr.Jagath Wansapala, Professor KKDS Ranaweera, Mrs Rupika Perera and the staff of Department of Food Science and Technology.

I am deeply indebted to Mr. Michael Perera, CEO/GM, CMC Engineering Export GmbH, for the facilities provided, encouragement and the support extended to me.

I also extend my sincere thanks to Mr. Kumar Borallessa, Director, Ceylon Tea Marketing Ltd, and his staff for providing me the materials for research, tea tasting and the support extended me during the research period.

I wish to acknowledge the support given by Mr. Dinesh Gupta, Managing Director - Bry Air Asia pvt Ltd as well as Mr. Raakesh Madan, Vice President Bry Air Asia pvt Ltd.

My special thank goes to Mr, M.P Wijeratne, Installation Engineer, CMC Engineering Export $\mathrm{GmbH}$ for his enormous contribution for the fabrication, installation and commissioning of the pilot plant and the Industrial plant.

I sincerely appreciate Mr. Viraj Udayanga, Marketing Executive, CMC Engineering Export $\mathrm{GmbH}$ for his support in various avenues to complete the research.

Finally, I would like to thank all my colleagues who helped me in numerous ways to complete this study. 